\title{
SPEED CONTROL OF INDUCTION MOTOR USING FUZZY RECURSIVE LEAST SQUARES TECHNIQUE
}

\author{
Santiago SÁncheZ ${ }^{1}$ \\ EdUARDo GiRALDO ${ }^{2}$
}

\section{Resumen}

Este artículo presenta el diseño de un controlador adaptativo, el sistema de control emplea lógica difusa adaptativa, modos deslizantes y es entrenado con la técnica de mínimos cuadrados recursivos. El problema de la variación de parámetros es resuelto con el controlador adaptativo; se utiliza un regulador interno PI con el cual se produce que el control de velocidad del motor de inducción sea realizado por medio de las corrientes de estator en vez de los voltajes. Se usa el modelo del motor en el sistema de coordenadas de flujo orientado del rotor para el desarrollo y prueba del sistema de control.

\section{Palabras clave}

Control adaptativo, lógica difusa, motor de inducción.

\section{Alostract}

A simple adaptive controller design is presented in this paper, the control system uses the adaptive fuzzy logic, sliding modes and is trained with the recursive least squares technique. The problem

1 M.Sc. Ingeniería Eléctrica, Instituto Tecnológico Metropolitano, Docente Investigador, santiagosanchez@itm.edu.co.

2 M.Sc. Ingeniería Eléctrica, Universidad Tecnológica de Pereira, Profesor Auxiliar, egiraldos@ohm.utp.edu.co 
of parameter variation is solved with the adaptive controller; the use of an internal PI regulator produces that the speed control of the induction motor be achieved by the stator currents instead the input voltage. The rotor-flux oriented coordinated system model is used to develop and test the control system.

\section{Key words}

Adaptive control, fuzzy logic, induction motor. 


\section{INTRODUCTION}

The induction motor (IM) has great variety of applications in industrial process when is used as fans or pumps, heating and air conditioning (Spiegel et al., 2003). The low cost and reliability makes preferable the use of the IM front other type of motor (Leonhard, 2001). The control of IM has a wide variety of techniques, actually the researchers focus their works in the method of vector control or field oriented control, in order to estimate the parameters of the machine Chiasson (2005) describes a polynomial method, Alogne et al. (2001) present a methodology with least squares and genetic algorithms by means off-line identification, alternative methods of identification use stochastic optimization (Ursem et al., 2004), Koubaa (2004) uses the identification procedure with the simple recursive least squares technique, the method is based on the steady state equations of the IM. A standstill on-line parameter estimation is proposed by Fang et al. (2005). The IM dynamic system is highly nonlinear, and has a coupling between flux and torque which makes difficult apply the conventional control. Chiasson $(1998,2005)$ employs the input-output linearization to control the speed and works with the model of field oriented coordinate system to design the controller system, the nonlinear control has the property to consider the whole dynamic of the system (Sastry, 1999). Bose (2002) presents the methods of scalar control, sensorless, vector control and an advanced scalar control technique, known as direct torque control but has a disadvantage at low speed. These and other methods are affected by the parameter variations and to solve this problem, adaptive nonlinear methods such as adaptive fuzzy control, adaptive input-output feedback linearization technique and adaptive sliding mode (Mezouar et al. 2007) have been used over the IM. The adaptive fuzzy control uses the recursive least square training (Wang, 1992) and is developed under consideration of vector control method, Juang et al. (2007) design a PID fuzzy improved and Chiang et al. (2005) increase the perform of the controller with the addition of heuristic 
optimization to tune the fuzzy system, Kim et al. (2006) made an identification an tune by the combination of fuzzy and genetic algorithm, an online neuro-fuzzy tuning procedure to adjust the PID gains is describe in (Kim et al. 2006) In (Rehman et al., 2007) an adaptive fuzzy controller is designed but a disadvantage of this system is the training based on the gradient rule to update the approximator parameters, this technique is computationally more expensive than the fuzzy adaptive recursive least squares training system proposed. The principal reason to apply the adaptive fuzzy technique is due that the IM model is a nonlinear system and traditional linear controllers fail at the moment to be used in a entire range of speed operation, linear methods require a linearization around an operating point, additionally the linear controllers need a previous knowledge of parameters of the system to regulate appropriately the plant, a reason to avoid the artificial neural network is the difficult train and modeling.

The aim of this work is the design of a speed controller for the induction motor using an adaptive fuzzy tuning. The sections describe the induction motor model, the controller design and the results.

\section{INDUCTION MOTOR MODEL}

The model of the electric machine uses the rotor-flux field oriented coordinate system described in (Chiasson 2005), in which is clear and simple to design a speed controller. This model reduces the task of work with two axis of the rotor flux and uses a polar coordinate representation. The system in state space representation is presented in equations (1-6), with $\theta$ the angular position in $\mathrm{rad}, \omega$ the angular speed in $\mathrm{rad} / \mathrm{s}, i_{d}$ and $i_{q}$ represents stator currents in the direct and quadrature axis respectively, $\varphi_{d}$ the magnitude of the rotor field flux, while $\rho$ is the angle of the rotor field flux.

The electrical and mechanical parameters are $R_{r}, R_{s}$ rotor and stator resistances respectively, $L_{s}, L_{r}$ y $L_{m}$ are the stator, rotor and coupled inductances, $\mathrm{J}$ is the moment of inertia, $\mathrm{f}$ is the 
viscous damping constant and $T_{L}$ is the load torque. For simplicity is usually used $\sigma=1-L_{m} /\left(L_{s} L_{R}\right)$ the linkage factor, $\eta=R_{R} / L_{R}$ the inverse of time constant, $n_{p}$ number of poles pair, $\mu=n_{p} L_{m} /\left(J L_{R}\right)$ and $\mathrm{Y}=L_{m}^{2} R_{R} /\left(\sigma L_{R}^{2} L_{s}\right)+R_{s} /\left(\sigma L_{s}\right)$.

$$
\begin{aligned}
& \frac{d \theta}{d t}=\omega \\
& \frac{d \omega}{d t}=\mu \varphi_{d} i_{q}-\frac{f}{J} \omega-\frac{T_{L}}{J} \\
& \frac{d \varphi_{d}}{d t}=-\eta \varphi_{d}+\eta L_{m} i_{d} \\
& \frac{d i_{d}}{d t}=-\gamma i_{d}-\left(\frac{\eta L_{m}}{\sigma L_{s} L_{r}}\right) \varphi_{d}+n_{p} \omega i_{q}+\eta L_{m} \frac{i_{q}^{2}}{\varphi_{d}}+\frac{u_{d}}{\sigma L_{s}} \\
& \frac{d i_{q}}{d t}=-\gamma i_{q}+\left(\frac{L_{m}}{\sigma L_{s} L_{r}}\right) n_{p} \omega \varphi_{d}-n_{p} \omega i_{d}-\eta L_{m} \frac{i_{q} i_{d}}{\varphi_{d}}+\frac{u_{q}}{\sigma L_{s}} \\
& \frac{d \rho}{d t}=n_{p} \omega+\eta L_{m} \frac{i_{q}}{\varphi_{d}}
\end{aligned}
$$

\section{Controller design}

This section presents the technique of nonlinear adaptive control and the sliding modes control. The main idea is to design a field oriented vector control scheme, the method lets control the torque of the induction motor with a decoupling between the torque and flux. Note that the electromagnetic torque $T_{e}=J \mu \varphi_{d} i_{q}$ is the product of two state variables and at the same time depends of the magnitude of the rotor flux. In field oriented control the flux along of the $q$-axis should be zero and in this way the flux is aligned along the $d$-axis. If the condition mentioned before agree and the flux is kept constant then the current $i_{q}$ will control the speed and now the control system looks like a dc machine controller (Chiasson 1998), (Bose 2002). 
The developed method in this work is the direct adaptive fuzzy control, which uses an adaptive fuzzy approximator to approximate the controller, and guarantee that the output error decreases.

The control law $u$ is approximated through a training of fuzzy logic systems using recursive least squares (FRLS) and sliding mode (SM), the system is given by (7).

$$
\dot{y}=f(x)+g(x) u
$$

Where $\mathrm{y}$ is the output of the system, $f(x)$ and $g(x)$ are smooth vector fields. There exist $g_{0}$ and $g_{1}$ such that $0<g_{0} \leq g(x)<g_{1}<\infty$, and exist $G(x) \geq 0$ such that $|\dot{g}(x)|=\left|\frac{\partial g}{\partial x} \dot{x}\right| \leq G(x)$ for all $x \in S_{x}$.

where $S_{x} \subseteq \Re^{n}$ is the space of the state trajectory. Using feedback linearization we have an ideal control law in (8).

$$
u=\frac{1}{g(x)}(-f(x)+u(t))
$$

where $u(t)=\dot{y}_{m}+\delta e_{s}+\bar{e}_{s}, \bar{e}_{s}=\dot{e}_{s}-\dot{e}_{0}$ and $\delta>0 . \quad y_{m}$ is the desired output trajectory, the tracking error is defined by $e_{s}$ and $e_{0}=y_{m}-y$, thus $\bar{e}_{s}=\dot{e}_{s}-\dot{e}_{0}$, such that $e_{s}=e_{0}$.

The goal of the adaptive controller is to learn how to control the plant to carry the tracking error close to zero. The control law $u$ could be expressed like the equation (9).

$$
u=\hat{u}_{d}+d_{u}(x)
$$

Where $\hat{u}_{d}$ is the controller approximated by FRLS (Wang, 1992, 1994), $d_{u}(x)$ is the bounded approximation error. Then consider the direct adaptive controller (Rehman et al., 2007):

$$
u_{d}=\hat{u}_{d}+u_{s d}
$$

In (10) $u_{s d}=k \operatorname{sgn}\left(e_{s}\right)$ is a term of control by sliding modes, where $k$ is the constant that ensures that $y, \hat{u}_{d}$ and $u_{s d}$ are bounded, and the error magnitude goes to zero or near to zero. 


\section{Results}

Induction motor parameters used in simulations are $R_{s}=0,19$ $\Omega, R_{r}=0,39 \Omega, L_{r}=4,6 \mathrm{mH} L_{s}=4,20 \mathrm{mH}, L_{m}=4,00 \mathrm{mH}, \mathrm{np}=$ $2, \mathrm{~J}=0,0226 \mathrm{Kgm}^{2}, \mathrm{f}=0,00014 \mathrm{Nm} / \mathrm{rad} / \mathrm{s}$. Simulation results are shown in Fig. 2, 3 and 4, the load torque is set constant in 5 $\mathrm{Nm}$, the initialization values of the FRLS to adaptive training are set in the same way like the values of the linear recursive least squares algorithm. An internal PI is used such that the stator currents are the control variables. The current by the $d$ axis is kept constant and then the current $i_{q}$ is employed to control the IM and is the other reference of the PI regulator, this can be seen in the resulting system of Fig. 1, we can appreciate the full control system implemented; where the FRLS controller uses the tracking error and produce a part of the current reference, the other part is produced by the sliding controller.

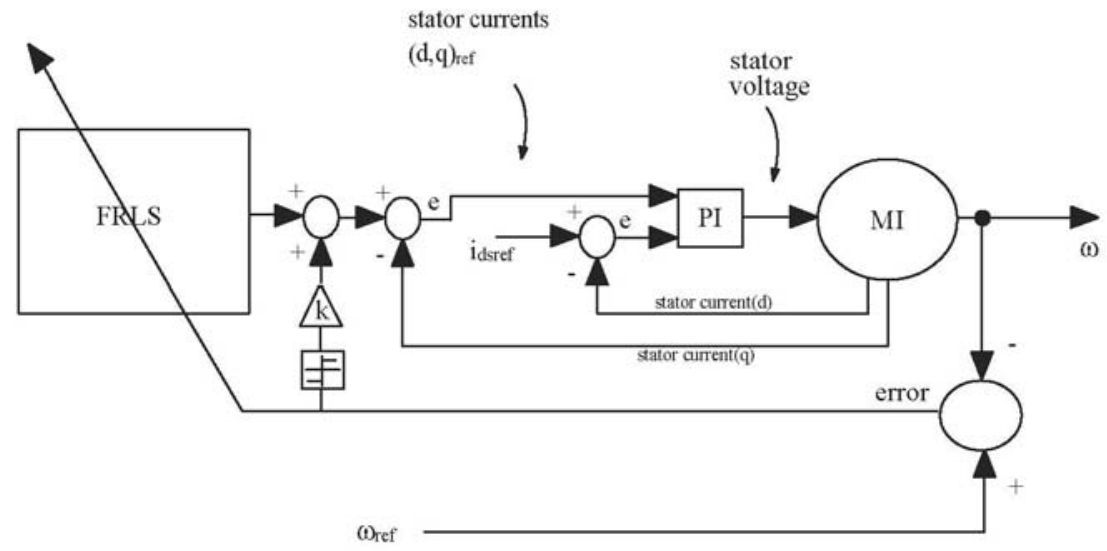

Fig. 1. SYSTEM MODEL

Fig. 2 presents the speed variation in closed loop, at the beginning the system output has an error respect to the speed reference which is reduced around $0.1 \mathrm{~s}$, this can be also observed in the plot of the tracking error (Fig. 3); due to the parameter 
initialization of the adaptive system, the pull up of the motor is lead to final speed $(188 \mathrm{rad} / \mathrm{s})$ in a smooth way. Fig. 4 shows the stator current variation with a speed change and we can see the rotor flux performance. The stator currents and the rotor flux stand inside the limits of the motor.

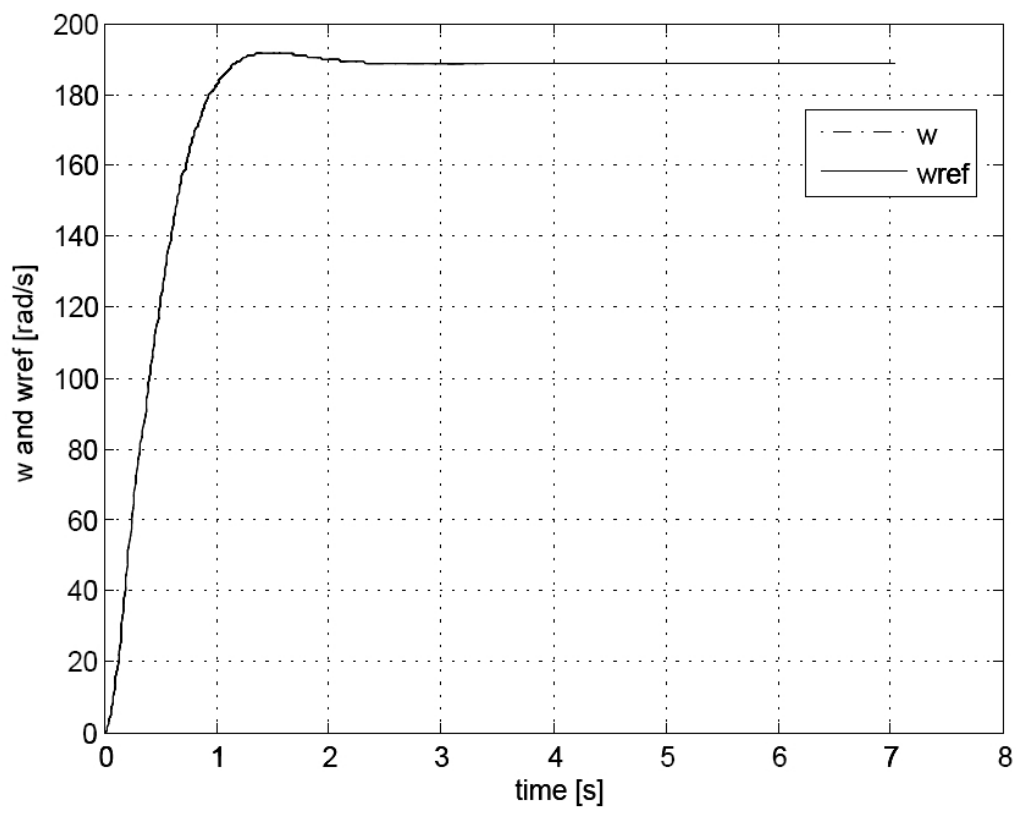

Fig. 2. MotoR SPEED AND REFERENCE SPEED

Fig. 5 shows the behavior of a conventional PID and the hybrid fuzzy recursive method is in Fig. 2. The start of the motor is made with the fuzzy controller and the PID, a lower mean square error (MSE) is achieved by the adaptive controller. Table 1 shows this comparison, where performance of the hybrid controller (Fuzzy RLS and SM) is higher than the others controllers. The MSE is computed like (11) with $\mathrm{T}=7 \mathrm{~s}$ and $\mathrm{T}=5 \mathrm{~s}$ respectively. 


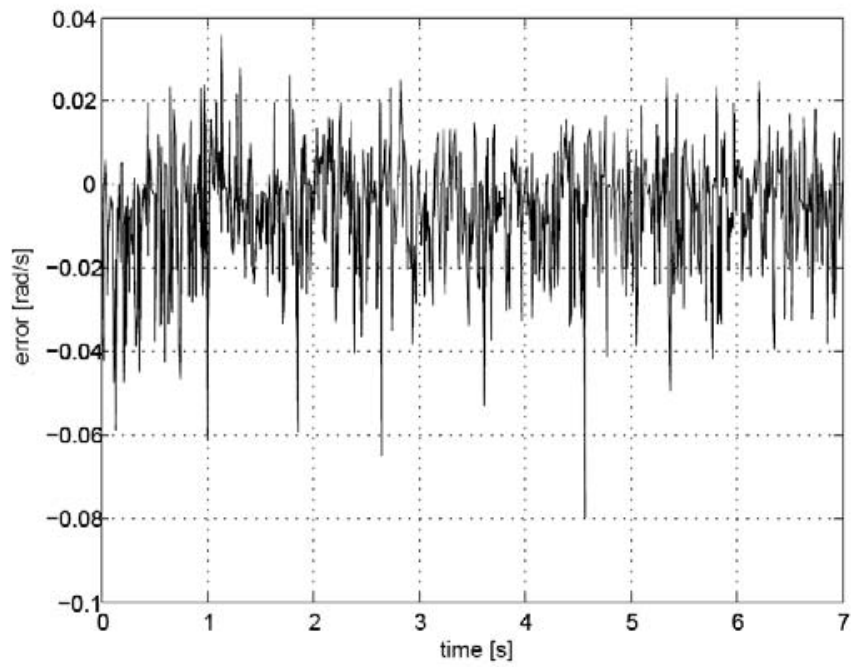

FIG. 3. TRACKING ERROR

$$
M S E=\frac{1}{T} \int_{t=0}^{t=T} e^{2} d t
$$

TABLE 1. MSE SUMMARY FOR THE CONTROLLERS

\begin{tabular}{cc}
\hline ConTROLLER & MSE $\left(\mathrm{T}_{\mathrm{L}}=5 \mathrm{Nm}\right)$ \\
\hline PID & 0,7980 \\
Fuzzy RLS and SM & 0,0026 \\
\hline
\end{tabular}

In order to make a comparison of the performance shown in Rehman et al. (2007), when the $T_{L}=0 \mathrm{Nm}$ and highlighting that they did not give information of the used induction motor parameters, from the table 2 we can observe that the MSE obtained with the training FRLS algorithm is lower, and the tracking error of Fig. 6 shows a similar behavior to the error of Fig. 3, but has the peak around $3 \mathrm{rad} / \mathrm{s}$. To make comparisons we convert the error from $\mathrm{rad} / \mathrm{s}$ to $\mathrm{rpm}$ and later calculate the MSE. The speed and reference speed in Fig. 7 reach the $188 \mathrm{rad} / \mathrm{s}$. 
TABLE 2. MSE SUMMARY

\begin{tabular}{cc}
\hline CONTROLLER & MSE $\left(\mathrm{T}_{\mathrm{L}}=0 \mathrm{NM}\right)$ \\
\hline Direct adaptive fuzzy & 5,0749 \\
Indirect adaptive fuzzy & 8,798 \\
Fuzzy RLS and SM & 0,7768 \\
\hline
\end{tabular}

\section{Conclusion AND DISCUSSION}

It has been shown a speed controller of the induction motor through a combined technique that employs the fuzzy logic and sliding modes. The intelligent controller implemented in this work gives an advantage over the classical nonlinear and linear control techniques because it considers the parameter variation and therefore controller parameters are estimated in an adaptive form. The adaptive technique makes unnecessary the use of a flux estimator that makes computationally heavy the system. Fig. 3 shows that tracking error tends to zero at the beginning of the implementation controller, which shows the performance of the controller implemented. The fuzzy adaptive controller uses the heuristic and the mathematical model to be implemented; this gives the advantage over other controllers.
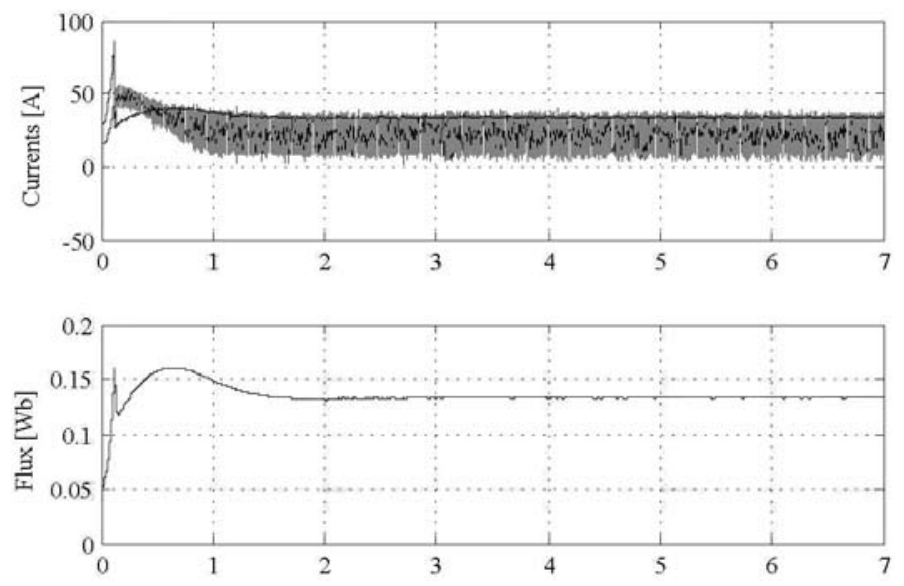

Fig. 4. STATOR CURRENTS AND ROTOR FLUX 


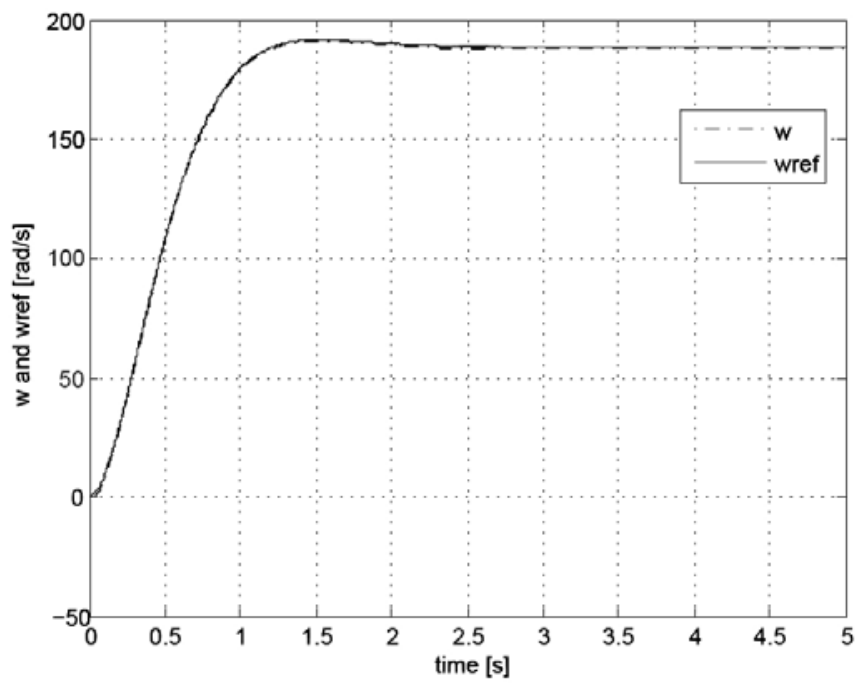

FIG. 5. PID SPEED CONTROL

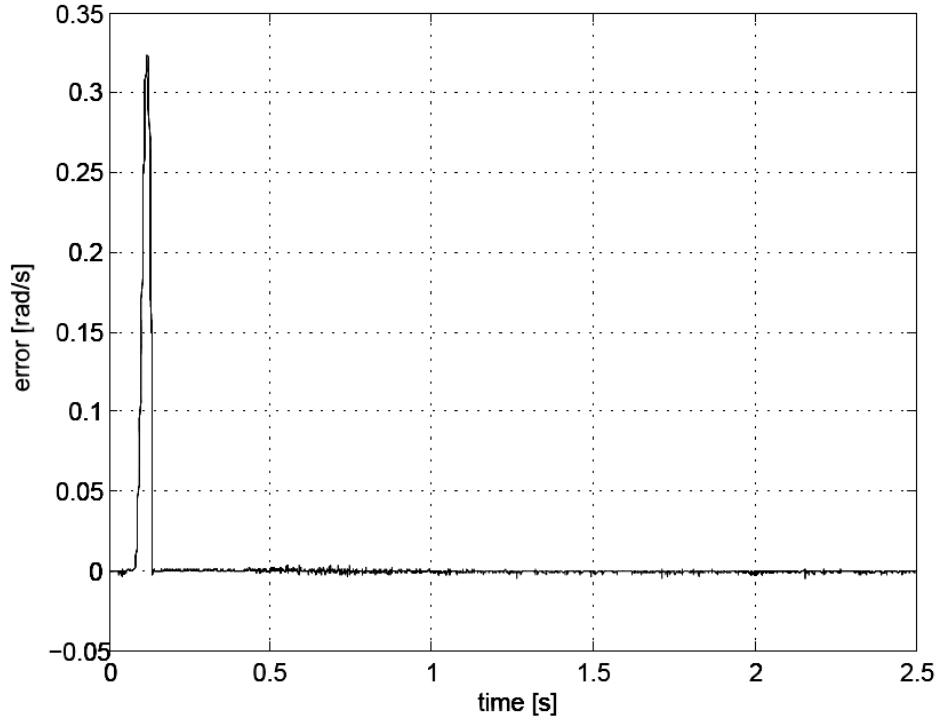

Fig. 6. $T$ Racking ERROR $T_{L}=0 \mathrm{NM}$ 


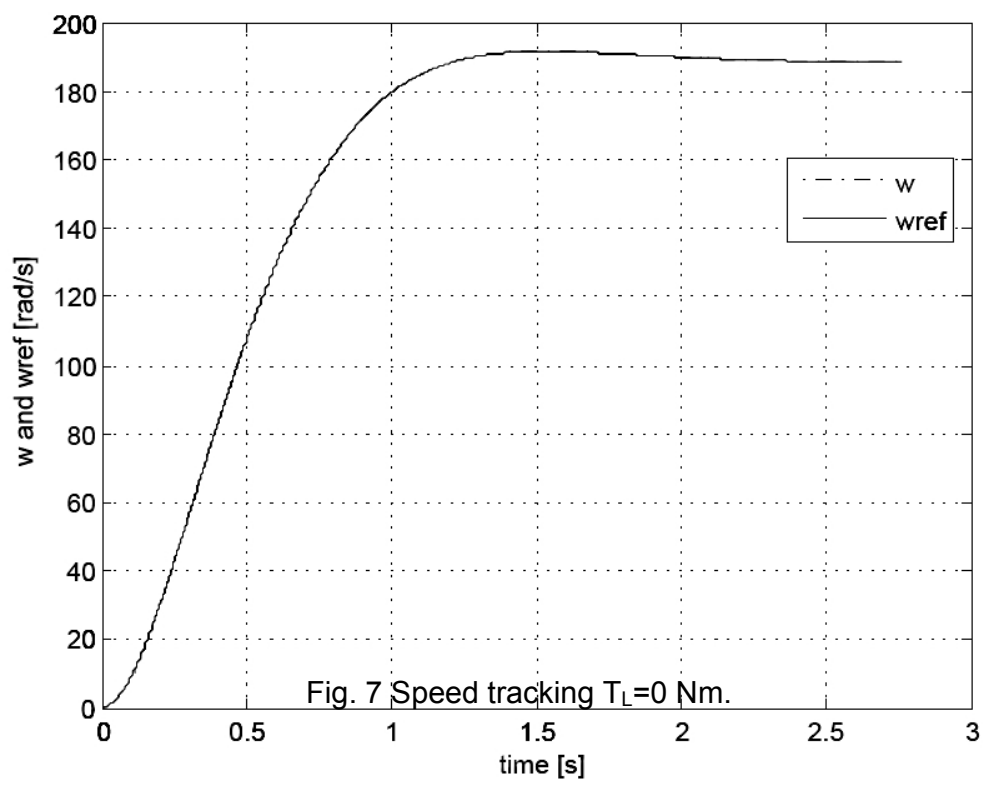

Fig. 7. SPEed tRACKING $T_{L}=0 \mathrm{NM}$

\section{REFERENCES}

Alogne, F. D’Ippolito, F. and Raimondi, F. M. (2001). Least squares and genetic algorithms for parameter identification of induction motor. Control engineering practice. 9. 647-657.

Bose, B. K. (2002). Modern Power Electronics and AC Drives. United States of America: Prentice Hall.

Chiang, C. L. and Su, C. T. (2005). Tracking control of induction motor using fuzzy phase plane controller with improved genetic algorithm. Electric power system research.73. 239-247.

Chiasson, J. (1998). A new approach to dynamic feedback linearization control of an induction motor. IEEE Transactions on Automatic Control, 391-397.

Chiasson, J. (2005). Modeling and High Performance Control of Electric Machines. New Jersey: IEEE Press on Power Energy, Wiley-Interscience. 
Fang, C. H. Lin, S. K. and Wang S. J. (2005). On-line parameter estimator of an induction motor at standstill. Control engineering practice. 13. 535540 .

Juang, Y. T. Chang, Y. T. and Huang, C. P. (2008). Design of fuzzy PID controllers using modified triangular membership functions, Information sciences, international jurnal. 178. 1325-1333.

Kim, S. M. and Han, W. Y. (2006). Induction motor servo drive using robust PID-like neuro-fuzzy controller. Control engineering practice. 14. 481487.

Koubaa, Y. (2004). Recursive identification of induction motor parameters. Simulation modeling practice and theory. 12. 363-381.

Leonhard, W. (2001). Control of electrical drives. Third edition. Springer.

Mezouar, A. Fellah, M. K. and Hadjeri, S. (2007). Adaptive sliding mode observer for induction motor using two-time-scale approach. Electric power system research. 77. 604-618.

Rehman, H. and Nounou, H. N. (2007). Application of fuzzy control to ac machines. Applied soft computing. 899-907.

Sastry, S. (1999). Nonlinear Systems, Analysis stability and control. Springer.

Spiegel, R.J. Turner, M.W. and McCormick, V.E. (2003). Fuzzy-Logic-based controllers for efficiency optimization of inverter-fed induction motor drives. Fuzzy sats and systems.137. 387-401.

Ursem, R.K. and vadstrup, P. (2004). Parameter identification of induction motor using stochastic optimization algorithms. Applied soft computing. 49-64.

Wang, L. X. and Mendel, J. M. (1992). Fuzzy basis functions, Universal approximation, and orthogonal least-squares learning. IEEE Transactions on neural networks. 3. 5. September. 807-814.

Wang, L. X. (1994). Adaptive Fuzzy Systems and Control. Design and stability. New Jersey. Prentice Hall. 
